\title{
Direct electrooxidation of 3-methyl-4-nitrophenol (MNP) at carbon fiber microelectrode (CFME)
}

\author{
Yibor Fabrice Roland Bako ${ }^{1}$, Issa Tapsoba ${ }^{1,}$, Maxime Pontie ${ }^{2}$, Mohamed Lyamine Chelaghmia ${ }^{3}$ \\ ${ }^{1}$ Laboratoire de Chimie Analytique Environnementale et Bio-Organique, Département de Chimie, \\ Université Ouaga I, 03 BP 7021 Ouagadougou 03, Burkina Faso \\ ${ }^{2}$ Université d'Angers, SFR Santé, Laboratoire GEIHP EA 3142, Institut de Biologie en Santé, PBH- \\ IRIS, CHU, 4 Rue Larrey, 49933 Angers Cedex 9, France \\ ${ }^{3}$ Département de Génie des Procédés, Laboratoire d'Analyses Industrielles et Génie des Matériaux, \\ Université 8 Mai 1945 Guelma, BP 401, Guelma, Algeria \\ *E-mail:issa.tapsoba@gmail.com, issa.tapsoba@univ-ouaga.bf
}

doi: $10.20964 / 2018.08 .35$

Received: 23 April 2018 / Accepted: 6 June 2018 / Published: 5 July 2018

The direct electro-oxidation of 3-methyl-4-nitrophenol (MNP), main by-product of the insecticide fenitrothion (FT), both endocrine disruptors, leads to carbon electrode passivation due to electrodeposition of polyphenol on electrode surface. To overcome this problem usual electrochemical cleanings, help the users to treat the electrode surface. Due to the little diameter of the carbon fiber, this solution is unusable for a carbon fiber microelectrode (CFME). We proposed presently, for the first time on a CFME, an original anti-passivating strategy based on the optimization of the initial oxidation potential $(-1.2 \mathrm{~V}$ vs $0 \mathrm{~V} / \mathrm{Ag} / \mathrm{AgCl})$ with or without a CFME modification by a film of nickel tetrasulfonated phthalocyanine (p-NiTSPc) electrodeposited in alkaline solution. This original strategy was studied in the light of electrode sensitivity dedicated to MNP analysis.

Keywords: CFME; MNP; Electrochemical cleaning, anti-passivation, initial potential; p-NiTSPc film

\section{FULL TEXT}

(C) 2018 The Authors. Published by ESG (www.electrochemsci.org). This article is an open access article distributed under the terms and conditions of the Creative Commons Attribution license (http://creativecommons.org/licenses/by/4.0/). 